\title{
INTRODUCCIÓN A LA CONFIGURACIÓN NARRATOLÓGICA DE LOS CONCEPTOS LITERARIOS DE HÉROE Y ANTIHÉROE
}

\author{
Francisco ÁLAMO FELICES \\ Universidad de Almería
}

\begin{abstract}
S i tomamos, como punto de partida, la orientación teórica que nos proporciona un estricto enfoque narratológico -que vendría a coincidir con la definición que de este concepto ofrecen Marchese y Forradellas (1994)-:

El héroe es el personaje principal o protagonista de unos acontecimientos, el actor de una representación muy variada detrás de la cual se pueden entrever o adivinar esquemas generales o funciones codificadas; de igual manera, en una teoría actancial, se piensa que la variedad de los personajes puede reconducirse a un modelo bastante simplificado. Desde este punto de vista no existe una tipología plausible del héroe, que es simplemente un personaje (Marchese y Forradellas, 1994: 194).
\end{abstract}

La figura literaria del héroe puede abordarse desde una doble perspectiva. En primer lugar, y según la teoría morfológica de V. Propp, el héroe correspondería a uno de los siete dramatis personae que pueden aparecer en los cuentos maravillosos:

En su famoso estudio Morfología del cuento (1928), Propp, derivando su análisis de la comparación de los motivos y partes constitutivas de los cuentos maravillosos tradicionales rusos, plantea que no son las funciones ni los roles de los personajes los que cambian, sino tan sólo sus nombres y atributos, relacionados con su aspecto, nomenclatura, forma de entrada en escena y hábitat. Según Propp, los personajes, que serían factores subsidiarios respecto a las funciones -puesto que sobresalen fundamentalmente en tanto que esferas de acción en torno a las que se agrupan aquellas-, no varían tampoco en su tipología funcional, pudiéndose distinguir básicamente siete: el agresor o malvado, el donante/donador o proveedor -causa-, el auxiliar, la princesa o personaje buscado, el mandatario -fin-, el héroe y el falso héroe (Valles, 2002: 343-344). ${ }^{1}$

Además, la morfología proppiana tampoco escapa, tanto en la distribución que realiza de las funciones entre los personajes como en el propio desarrollo de las mismas,

\footnotetext{
${ }^{1}$ «Una aplicación de esta tipología a una novela concreta, por ejemplo a Barcelona Connection (1988) de Andreu Martin, resultará prácticamente idéntica -con la incorporación del falso héroe, que también introducirá luego Greimas (1970) como traidor-a la de su organización actancial» (Valles, 2002: 344).
} 


\section{Tropelías. Revista de Teoría de la Literatura y Literatura Comparada, 19 (2013) Introducción a la configuración narratológica de los conceptos de héroe y antihéroe}

de la centralidad y supremacía de la figura del héroe en su configuración ético-moral y sociológico-histórica en las historias en las que aparece. Es así como se entiende que Propp le atribuya al héroe la consecución triunfalista de la última función -el matrimonio - tras el largo y accidentado periplo anterior que debe superar:

Es incluso cuando la semiótica greimasiana intenta descronologizar y vaciar de contenidos sicológicos el papel de los actantes, cuando es difícil desligar la relación sujeto/ objeto de los sentidos de la búsqueda y de la conquista que una amplia tradición cultural ha invertido sobre todo en el protagonista de la narrativa (Reis y Lopes, 1996: 117).

Sin embargo, y siguiendo el análisis que del modelo funcional proppiano realiza R. Selden, puede advertirse en el mismo

[...] cierta simplicidad arquetípica que hace necesaria cierta elaboración a la hora de aplicarlas a textos más complejos. En el mito de Edipo, por ejemplo, Edipo se enfrenta al problema de resolver el enigma de la esfinge, el problema se resuelva, el héroe es reconocido, se casa y sube al trono. Sin embargo, Edipo es al mismo tiempo el falso héroe y el villano, queda en evidencia (mató a su padre, en el camino a Tebas y se casó con su madre, la reina) y se castiga a sí mismo (Selden, 2001: 94-95).

Y es que, como señalan Reis y Lopes (1996), cualquier análisis teórico centrado sobre este concepto del héroe

[...] se relaciona directamente con una concepción antropocéntrica de la narrativa: se trata de considerar que la narrativa existe y se desarrolla en función de una figura central, protagonista cualificado que se destaca por esa condición de las restantes figuras que pueblan la historia. Ésta y las categorías que la estructuran son, pues, organizadas en función del héroe, cuya intervención en la acción, posicionamiento en el espacio y conexiones con el tiempo contribuyen a revelar su centralidad indiscutible (Reis y Lopes, 1996: 117).

Ahora bien, si utilizamos una visión del sentido narrativo más general, situaríamos al héroe (Ducrot y Schaeffer, 1998) ${ }^{2}$ como el protagonista central y vector de una

\footnotetext{
2 «Según la importancia del papel que asumen en el relato, los personajes pueden ser principales (los héroes, los protagonistas) o secundarios, que se limitan a tener una función episódica. Esta oposición, desde luego, no siempre resulta evidente, con lo que se admiten numerosas posiciones intermedias. La noción de héroe ha sido criticada con frecuencia, incluso más que la de personaje. No obstante, tiene a su favor el hecho de que puede servir para dar cuenta adecuada de la descripción de las jerarquías de personajes, a pesar de que estas jerarquías resulten a veces difíciles de establecer (no siempre nos encontramos con criterios textuales tan claros como los que aparecen en el teatro clásico, donde sólo los héroes tienen derecho a los monólogos, mientras que los personajes secundarios sólo intervienen en los diálogos). Asimismo, dicha noción también es relevante en el estudio de las relaciones entre los textos y los sistemas de valores, pues estas relaciones se encuentran con frecuencia determinadas por la mediación de un personaje-héroe al que al autor atribuye los valores positivos: "La relación emocional hacia el héroe (simpatía-antipatía) se desarrolla a partir de una base moral. Los tipos positivos y negativos son necesarios para la fábula [...] El personaje que recibe la carga emocional más fuerte se llama héroe" (Tomachevski). Las jerarquías morales y las jerarquías funcionales no coinciden necesariamente: el personaje que asienta la axiología de un relato o de una obra de teatro no es necesariamente el actantesujeto, puede ser también el actante vencido, etc. (Hamon, 1984). En definitiva, el héroe no puede definirse siempre en un solo nivel (por ejemplo, o bien como actante-sujeto, o bien como personaje que aparece con más frecuencia): su determinación procede en muchos casos de la conjunción de
} 
narración, estructura que se muestra de manera paradigmática en determinadas modalidades fantásticas -la novela caballeresca o bizantina- o épicas -la epopeya, el poema épico o el cantar de gesta-. Suele ser muy común que esta conceptuación del héroe conlleve una conformación centrípeta del relato en la que toda la arquitectura narrativa gira en torno a esta figura central, y, además, salvo que se utilicen recursos como la ironía o la parodia, el narrador desgranará continuamente a lo largo de la historia los valores y acciones de este. Esto es:

\footnotetext{
El término de héroe, en el terreno de la literatura, puede aludir al protagonista de un relato, de un poema o de una obra de teatro, a ese personaje que se diferencia de todos los demás, que con sus actos representa a un tipo de individuo, refleja el imaginario de un autor y/o de una época, y permite así observar qué características esenciales encarnan el deseo fundamental del hombre en un momento determinado. El héroe literario va a ser en este sentido el ejemplo personalizado de un siglo, la representación y el arquetipo de una norma. Por otra parte hay que señalar que este héroe, a pesar de morir en la ficción, permanece vivo a través de la historia literaria, en la lectura y, en este sentido, se acerca al concepto de mito en cuanto que la eternidad de la literatura le hace inmortal (De Diego, 2000: 57).
}

Por otra parte, la teoría literaria y narrativa contemporánea también se ha acercado a la figura del héroe aportando diversas tipologías, y así, aparte de la concepción de L. Goldmann de la novela en tanto que lucha del protagonista contra el universo novelesco, destacan las propuestas de G. Lukács (1920) y de N. Frye (1957).

El análisis lukacsiano, realizado en su etapa de influencia hegeliana, desarrolla al héroe de la novela contemporánea como un sujeto siempre problemático o en continuo conflicto con el mundo y al que clasifica, en su actuación, de tres maneras:

a) Evasión de la realidad: novelas del idealismo abstracto.

b) Rechazo de la realidad y actúa al margen o en contra de ella: novelas del romanticismo de la ilusión.

c) Aprendizaje e integración: novela de aprendizaje o Bildungsroman ${ }^{3}$.

La novela será, para Lukács, el molde por excelencia para instituir al héroe en tanto que entidad individualizada, así si en la «epopeya», cuando aparece cuestionado el destino/sentido de la comunidad

\footnotetext{
procedimientos estructurales (por ejemplo, el personaje más importante desde el punto de vista funcional) y de un efecto de referencia axiológico a los sistemas de valores» (Ducrot y Schaeffer, 1998: 695).

3 «Término alemán (novela de educación o formación) para aludir, sobre el Wilhelm Meister (1795-1799) de Goethe -que ya apreciaba Lukács como modelo canónico del género y aunque la existencia de este es más antigua-, al relato de la historia de un personaje en su camino de formación diversa (sentimental, moral, intelectual) desarrollado entre la juventud y la madurez. Lukács y, tras él, Goldmann, especializan el término para designar a la novela que acaba con una autolimitación voluntaria por parte del héroe que acepta contentarse con los valores que le parecen empíricamente realizables, y que normalmente corresponden a una ideología dominante» (Valles, 2002: 246). Otros ejemplos de este tipo de narración podrían ser La educación sentimental (1869) de G. Flaubert, y, en España, Camino de perfección (1902) de P. Baroja y Tiempo de silencio (1962) de L. Martín-Santos.
} 
Introducción a la configuración narratológica de los conceptos de héroe y antihéroe

El sistema de valores acabado y cerrado que define el universo épico crea un todo demasiado orgánico para que en él un solo elemento esté en condiciones de aislarse, y de destacarse con suficiente elevación para descubrirse como interioridad y para hacerse personalidad (Lukács, 1970: 60),

en la novela, la psicología del héroe la denomina Lukács como «demoníaca», cuyo contenido deviene en la

[...] historia de esa alma que va por el mundo para aprender a conocerse, busca aventuras para afirmarse en ellas y, por esa prueba, alcanza su medida y descubre su propia esencia (Lukács, 1970: 85).

Para la mitocrítica de Frye ${ }^{4}$, las obras ficcionales pueden, también, articularse de acuerdo con las capacidades de acción del héroe que pueden ser mayores, iguales o menores que la nuestras, desplegándose, como consecuencia de las mismas, cinco posibilidades de relatos:

1. Relato mítico: Con héroe superior por naturaleza a otros y al entorno. Estaríamos ante un ser con potencialidades divinas, siendo la historia la plasmación de un mito.

2. Relato romántico: Con personaje propio de lo maravilloso que es superior en grado al resto y al entorno: «es el protagonista del relato fantástico (romance), de las leyendas y de los cuentos populares en las que encontramos como funciones típicas los prodigios, lo maravilloso, los encantamientos, las hadas y hechiceros, los animales que hablan, los talismanes, etc.» (Marchese y Forradellas, 1994: 195).

3. Relato supramimético: Cuando el héroe es superior al resto de personajes pero no al entorno, que correspondería a los personajes principales de la épica y de la tragedia.

4. Relato inframimético: Cuando se está a nivel de absoluta igualdad. Como en estas circunstancias no se estaría, pues, ante un paradigma heroico, estos personajes se presentan en las comedias y en las novelas y cuentos realistas.

5. Relato irónico: Si el hombre es inferior a los demás en poder o inteligencia.

Si desarrollamos más la tipología de Frye (y las consecuentes relaciones que mantiene, por lo demás, con la perspectiva hegeliana) puede ampliarse el anterior marco

\footnotetext{
${ }^{4}$ «En España, la más conocida aplicación de las teorías de Jung y Frye a la novela es el estudio de Juan Villegas La estructura mítica del héroe (1978) donde, tras examinar las posibilidades del método mítico así como la estructura mítica fundamental de la aventura del héroe, que constituía el mito literario central para Frye, compara Camino de perfección de Baroja, Nada de Laforet y Tiempo de silencio de Martín Santos para, pese a sus diferencias, observar el mismo esquema de la aventura mitológica del héroe en su relación con los ritos de iniciación y con las tres etapas fundamentales -la separación de la comunidad, la iniciación pasando por varias pruebas y el retorno- que guían su itinerario» (Valles, 2002: 67).
} 
esquemático y obtener una dimensión más profunda y efectiva de su aplicación al estudio de la figura del héroe literario.

Si, como hemos anotado, el modelo 1 de relato surgiría en los relatos míticos y el modelo 2 correspondería al de los cuentos maravillosos y a las leyendas y relatos fantásticos, el tercer tipo -que se engarzaría con el denominado por Hegel «héroe épico»- viene a coincidir con el significativo personaje de la tragedia griega:

Este personaje aparece dotado de una ascendencia superior (ha de ser de sangre real, o de procedencia aristocrática) y de unos poderes y cualidades extraordinarias. Su conducta debe ser ejemplar, de manera que los espectadores, identificados con él, puedan ser alcanzados por la catarsis, provocada por un sentimiento de temblorosa admiración hacia su grandeza de ánimo, o de piedad por su desgracia $\left[{ }^{5}\right]$. Este personaje lucha contra con destino aciago, ante el cual, acaba sucumbiendo. Un prototipo es la figura de Edipo [ $\left.{ }^{6}\right]$ (Estébanez Calderón, 1999: 501).

Era necesario este paréntesis, pues esta construcción de un personaje perseguido y desbordado por la fatalidad e inclemencia del destino será arquetípica en la tragedia renacentista y barroca. Será, por consiguiente, esta incontrolable fatalidad, promovida por la desbordante fuerza de las pasiones extremas, la que conducirá al héroe hacia su autodestrucción.

Muy relacionado con todo lo anterior es la variante del «héroe dramático» hegeliano, el cual, frente al modelo anterior, sí que es capaz de armonizar esa fuerza irracional de lo pasional con el entorno en el que se desenvuelve pudiendo evitar así el fracaso y la consiguiente autoaniquilación:

Ejemplo de este modelo de conducta sería el protagonista de La vida es sueño, Segismundo, que, después de una experiencia desafortunada durante su primera estancia en el palacio (donde se deja arrastrar por sus instintos de placer y dominación, que hacen suponer el triunfo de la fatalidad), recluido de nuevo en la torre, aprende, «desengañado», que «obrar bien es lo que importa», con lo que termina venciendo a «la inclemencia del hado» (Estébanez Calderón, 1999: 501).

Ahora bien, para que se produzca la aparición del héroe debe existir, en correspondencia, un tipo de sociedad con una serie de valores asimilados, practicados y comunes:

\footnotetext{
${ }^{5}$ Por lo demás, y según plantea M. Asensi (1998: 82), ambos sentimientos resultaban «morbosos a los ojos de la cosmovisión griega», por lo que «el revivirlos durante el espectáculo trágico hace que el espectador se libere de ellos».

${ }^{6}$ Recordemos la trayectoria de Edipo: ciego y sordo, despojado de su estado de dicha, inmerso en la desgracia y desesperación, mueve al espectador a la compasión. Quien asiste a la representación de esa obra experimenta piedad por ese hombre caído a causa de la voluntad de los dioses: «En concreto, nos provoca temor y piedad el que Edipo descubra que él es el causante de las desgracias que asolan la ciudad, precisamente porque ese descubrimiento está situado tras los planteamientos iniciales correspondientes a las propuestas de hallar un responsable, y tras los procedimientos a través de los cuales se descubre dicho responsable» (ibid., p. 82).
} 
Introducción a la configuración narratológica de los conceptos de héroe y antihéroe

Sin valores no hay héroe; sin valores compartidos, precisando más, no puede existir un personaje que permita la ejemplificación heroica. El héroe es siempre una propuesta, una encarnación de ideales. La condición de héroe, por tanto, proviene tanto de sus acciones como del valor que los demás le otorgan. Esto permite que la dimensión heroica varíe en cada situación histórica dependiendo de los valores imperantes. Independientemente del grado de presencia real de las virtudes en una sociedad determinada, ésta debe tener un ideal, una meta hacia la que dirigirse o hacia la que podría dirigirse (Aguirre, 1996: versión informática).

Dentro de la literatura medieval pueden rastrearse diversas modalidades del tipo del «héroe superior» que toman cuerpo tanto en los relatos caballerescos (es el caso de la tipología del personaje del caballero noble o de los vástagos de sangre real, como el del héroe Valtario ${ }^{7}$ ) como en los hagiográficos (el santo), que responden a las expectativas y al esquema ideológico de valores de los estamentos aristocráticos y religiosos dominantes en esos siglos ${ }^{8}$ :

Los «Libros» de caballerías comienzan por el «nacimiento» del héroe, exactamente igual que los libros picarescos. Pero ya dijimos que mientras en estos el nacimiento funciona simplemente como el límite originario de la «vida», en los textos organicistas el nacimiento supone ante todo una transcripción del valor (generalmente secreto para el héroe y los demás) sanguíneo (familiar o linajudo) que el héroe posee (Rodríguez, 1994: 271).

Esta modalidad de héroe se situaría en el segundo tipo propuesto por N. Frye.

Sin embargo, a partir del siglo XVI, aunque en los círculos cerrados y codificados de la aristocracia sigue perviviendo el modelo del «héroe clásico», comienzan a protagonizar las narraciones, ora de la novela realista ora de la comedia, personajes comunes de la vida cotidiana, esto es, seres normales del ámbito ciudadano y del trabajo manual o empresarial, desprovistos de cualquier linaje y que no son, por tanto, superiores ni a los demás hombres ni a su ambiente. Este nuevo discurso literario coincidiría con el cuarto tipo de relato de Frye.

Es especialmente sintomático cómo en algunos de esos textos se desgranan dos direcciones argumentativas que vienen a desembocar ambas en el descrédito literario y social de la figura del «héroe clásico»:

a) La primera, parodia, con sarcasmo, al anterior héroe caballeresco medieval (así, en El Quijote (1605-1615) cuyo protagonista sería, según la teoría de Lukács, un ejemplo claro del personaje problemático en busca de la identidad).

\footnotetext{
${ }^{7}$ Basado en una antigua saga germánica (anónimo, siglo IX), el cantar narra la hazaña de Valtario, héroe del reino godo de Tolosa en los años oscuros de las invasiones germánicas, allá por el siglo $\mathrm{V}$, su confinamiento y huida de la corte de Atila con su prometida, por la que combate derrotando a todo un ejército, su regreso triunfal a Aquitania y su boda con Hildegunda.

${ }^{8}$ «[...] las pruebas del héroe "muestran" no sólo su calidad superior (ante los demás caballeros, ante los demás hombres) sino también, a la par, la existencia de ese Orden (divino o caballeresco) que el héroe representa y que actúa en él» (Rodríguez Gómez, 1994: 287).
} 
b) La segunda, abre las puertas al tratamiento de la figura del antihéroe, especialmente desarrollado en los textos picarescos y que, como señala Juan Carlos Rodríguez:

[...] Lázaro y Lozana, y en gran medida Celestina, constituyen el primer intento de construcción «literal» de la actitud de «respuesta» de las clases inferiores ante la nueva situación que las reestructura. Pero esto es sólo una primera etapa de la picaresca. En cierto modo podemos decir que estos primeros libros picarescos son obras hechas desde una perspectiva que ha captado el «desorden» y que lo ha localizado, además y precisamente, en el lugar donde sus efectos son más destellantes: el lumpen del hombre (Lazarillo) y del sexo (Lozana) (Rodríguez, 1994: 60).

La novela picaresca va a consolidar y desarrollar en su disección de la corrupción social y moral de su tiempo:

[...] una trayectoria de degradación interior del héroe que se halla relacionada con su propio pasado, con sus experiencias desmoralizadoras y con su enfrentamiento a un mundo difícil y engañoso. La respuesta del héroe pícaro a su situación de inferioridad en el mundo social es la de convertirse en un burlador de los demás que utiliza las armas de la disimulación y el fraude. Por lo demás, todas las derivaciones de la picaresca en el siglo XVII acentúan sin excepción la estafa como una de las características esenciales de los héroes [...].

Por otra parte, los héroes de la picaresca tienen conciencia de que en sus vidas se cumple una reversión de los valores tradicionales consagrados, y utilizan las fórmulas de la parodia lingüística y literaria para describir numerosas situaciones en que se encuentran. Los esquemas genealógicos, por ejemplo, constituyen verdaderas parodias de la ascendencia noble en las altas jerarquías de la sociedad, al mismo tiempo que lo son de la genealogía de los héroes ideales en las novelas anteriores (Correa, 1977: 79-81).

Por lo demás, el modelo del héroe picaresco permanecerá, como figura arquetípica, hasta la actualidad ${ }^{9}$ :

El héroe pícaro sigue reencarnándose en diversidad de metamorfosis que mantienen viva su figura y su mensaje. Su trayectoria, una y varia, seguirá proyectándose en nuevas manifestaciones y posibilidades hacia el futuro. Su presencia nos ayuda a explorar aspectos significativos de la sociedad en que vivimos y sondear con mayor profundidad la índole del hombre y su destino (Correa, 1977: 94).

Ahora bien, como sabemos, determinadas circunstancias histórico-ideológicas producen un muy específico discurso literario que responde a la nueva episteme configurada. Lo que significa, por ejemplo, que cualquier referencia, en el caso de la literatura romántica, a la figura del héroe aparece íntimamente relacionada con el devenir histórico, ya que el siglo XIX trazará, al menos en una de sus caras más

\footnotetext{
${ }^{9}$ Desde el realismo decimonónico -Galdós en novelas como La desheredada (1881) o El doctor Centeno (1883)-, pasando por el Cela de la primera posguerra -Pascual Duarte (1942) y Nuevas andanzas y desventuras del Lazarillo de Tormes (1944)- hasta su influjo en la novela hispanoamericana contemporánea -El camino de Santiago (1967), de Alejo Carpentier; La ciudad y los perros (1963), de Vargas Llosa o Guía de pecadores (1972), del argentino Gudiño Kieffer-.
} 
representativas, un concepto de la Historia hermanado con la objetividad de la metodología de la ciencias naturales dentro de una confianza general en el progreso científico:

[...] y cuando ciertos autores comienzan a identificar a los héroes con individuos reales y necesarios, seres excepcionales en los cuales se encarna la Providencia y que, por lo tanto, están destinados a realizar grandes acciones capaces de determinar el proceso histórico. El mito entonces intenta adoptar una corporeidad. Este punto de vista está representado por autores como Hegel, quien visualiza a los héroes como videntes que conocen la verdad última de su mundo y de su tiempo. La Razón, según Hegel, se sirve de estos individuos excepcionales (quienes aparentemente sólo buscarán satisfacer su ambición personal) para cumplir sus fines trascendentes. La Idea Universal alcanza su finalidad a través de ellos (Velasco, 2000: versión informática).

Es así, también, como Rosa de Diego (2000), al plantear las características de la «literatura decadente» (situada entre el naturalismo y el simbolismo, alrededor de 1870) se detenga en connotar a la modalidad del héroe decadente:

Sus pensamientos y creaciones son singulares, excéntricos, insólitos. Y lógicamente, originales sus héroes, muchas veces también artistas, imágenes de su creador. Todos ellos no sólo raros, sino sobre todo extremadamente lúcidos y conscientes. El héroe decadente en su reacción de rechazo contra la sociedad y el medio, contra la vulgaridad, busca sobre todo la innovación [...]. La decadencia es por lo tanto fundamental desde el punto de vista de la modernidad [...].

El héroe decadente es además un neurótico y un anormal. Pero la originalidad de esta escritura, de su planteamiento, es que en una misma figura se reúnen el héroe de la novela, el individuo excéntrico y el artista. Y todo ello sin justificación alguna (De Diego, 2000: 59-60).

Sirvan de ejemplos literario-vitales de lo expuesto las trayectorias de autores como Huysmans, Villiers de l'Isle-Adam, Jean Lorrain, Élémir Bourges, Pierre Louÿs o Rachilde, que trasladan su nueva concepción desquiciada y despreciativa de lo burgués a sus «personajes-héroes», como des Esseintes de Huysmans o Monsieur de Bougrelon y Monsieur de Phocas de Jean Lorrain.

Sin embargo, del estudio anterior merece una especial reflexión el papel que la mujer -lo femenino- encarna en estos textos, en una muy interesante línea narrativo/ discursiva que oscila, de manera ambigua, entre lo pseudo-heroico (la nueva mujer artificial) y lo anti-heroico (o mujer malvada, sensualmente patologizada, vagina dentata):

La figura humana, el héroe decadente, se hace maniquí, pantomima, figura de guiñol, autómata, payaso, mimo, un ser de apariencia artificial, deshumanizado, sobre todo inquietante, siniestro y grotesco a la vez. La novela de Villiers de l'Isle-Adam, L'Eve future es también un claro ejemplo de esta estética de la apariencia. La Androide sustituye definitivamente a la mujer. No conoce la vida, ni la enfermedad, ni la muerte [...]. Una mujer artificial, perfecta y eterna, gracias a la utilización de todos los avances científicos, que sustituye definitivamente a la otra mujer, porque parecía más natural que la verdadera (Villiers, 1980: 296). [...] Puede llamarse Lilita, Eva, Salomé, Cleopatra. Una mujer convertida en objeto erótico. Puede ser ninfómana o frígida, mujer de fuego, mujer de hielo, 
pasiva o fría (Samain, 1939: 45). Hipersexual, hiposexual, pero siempre responsable del mal que azota a la sociedad. Un ser inferior física, fisiológica, psicológica y moralmente. En algunas ocasiones estos héroes decadentes prefieren incluso, antes que una relación física con una mujer, el contacto con una tela (De Diego, 200: 66-67).

Por otro lado, los protagonistas de la posterior narrativa realista y naturalista se configurarán como víctimas -antihéroes- del medio social en el que viven y que los condiciona, así

[...] ciertos personajes galdosianos, como Lázaro (La Fontana de Oro [1870]), Pepe Rey (Doña Perfecta [1876]), León (La familia de León Roch [1878]), jóvenes y de mentalidad liberal, fracasaron ante una sociedad conservadora y puritana, de la que habrían de marginarse o por la que serían destruidos (Estébanez Calderón, 1999: 502).

Dentro del catálogo de héroes, conformados históricamente, entre mediados del XVIII y finales del XIX (cuando el tratamiento de lo heroico está devaluado o casi olvidado), resulta especialmente interesante el análisis que realiza J. Aguirre (1996) entre los que él denomina héroe libertino, héroe romántico y héroe realista y sus posibles paralelismos en figuras relevantes de la política, de la literatura y de la sociedad del momento:

- El héroe libertino. La novela y el pensamiento libertino subraya de manera diáfana el estado de superioridad como aquel que se encuentra más próximo a lo natural que el correspondiente a la igualdad:

El héroe libertino, pues, rompe los vínculos con los valores comunes de la sociedad y sólo se ofrece como modelo a una minoría a la que intenta llevar a su lado. Su propósito es un desenmascaramiento de lo social como algo meramente convencional y la proposición de lo natural como lo auténtico. Sin embargo, el libertino ha descubierto que si la forma de ayudar a la naturaleza es la violencia y el crimen, esto se puede desarrollar mejor desde su privilegiada posición social. Hay un aspecto capital en los libertinos: la hipocresía. Aunque se haya descubierto que la esencia de la sociedad es la mentira, esa misma mentira debe servir para proteger sus desmanes. El héroe libertino vivirá engañado, utilizando la hipocresía como arma. Su exterior, la máscara con la que se presenta ante los otros, suele ser el del virtuoso. Es difícil ver a un libertino actuando a cara descubierta. Es más probable verle presentándose como un noble respetable, disfraz que le resulta más útil para conseguir sus propósitos (Aguirre, 1996: versión informática).

- El héroe romántico. Cuyos representantes más significativos son, para Aguirre, Lord Byron y Friedrich Hölderlin:

El heroísmo romántico procede, en gran medida, de su soledad. El héroe se encuentra dolorosamente solo con una verdad que le llena pero que es incapaz de hacer comprender a los otros. Se asemeja a la figura de los profetas [...]. La función profética del héroe romántico es la de transmitir a los demás hombres la verdad que le ha sido revelada. Cuál sea esta verdad es algo que varía de unos románticos a otros, pero es común en la mayoría sentirse despreciados por una sociedad insensible que se ríe de su patetismo. El héroe romántico por excelencia es el artista. Nunca se había elevado tan alto como durante el romanticismo la consideración del genio artístico. Su propia naturaleza de genio 
le convierte ya en un rebelde: no sigue las normas de los otros, son los otros los que deben seguirle a él (Aguirre, 1996: versión informática).

- El héroe realista. Este tipo de héroe, frente al romántico, no puede realizar ningún tipo de introspección, ya que se presenta siempre como un hombre de acción social. La figura histórico-heroica de Napoleón Bonaparte tendrá su repercusión literaria en personajes, señala Aguirre, que pueden denominarse «napoleones literarios» como el Julián Sorel de Stendhal, o el Raskolnikov de Dostoievski:

El héroe realista es consciente de dos cosas: que los límites de la batalla son los de la historia, los de lo social, y, en segundo lugar, de la debilidad del enemigo. Los héroes realistas no quieren la gloria, como los románticos, quieren los beneficios de la fama, el reconocimiento social. Se parte del principio de que la sociedad es una entidad mediocre, el espacio del engaño, en el que cada uno ocupa un lugar conforme a lo que tiene y no a lo que es realmente. El héroe ya no necesita ser noble. El héroe prototípico del realismo no es revolucionario, sino que, por el contrario, necesita del orden existente para poder desplazarse (Aguirre, 1996: versión informática).

Por último, en la narrativa y en la dramaturgia del siglo XX, la configuración de lo heroico va a ser cuestionada y soslayada de manera casi definitiva desde dos perspectivas. Una respondería a planteamientos ideológico-sociales, como la aparición de los grupos sociales o del denominado héroe colectivo que va a ser el tipo de personaje que pondrá en práctica la denominada novela social de los años cincuenta y sesenta del pasado siglo y que tuvo en España un muy especial desarrollo y tratamiento, el cual resumimos en estas líneas:

[Este personaje] podía ser un grupo social o una individualidad representativa «que asume el papel de héroe múltiple, epopéyico [en el primer caso, o bien] un personaje central que aparece formando parte de un sector de la sociedad y, que a pesar de tener personalidad propia, es reflejo de las idiosincrasias del grupo en cuyo ambiente se mueve, es un símbolo representativo, un personaje-clase, una síntesis, o si se quiere la imagen de ciertas gentes. [Este tipo específico -representativo- busca] hacer patente la problemática que afecta a todo un sector de la sociedad por medio de un caso particular [pues] [...] particularizándose y generalizándose continuamente, se pone de relieve lo específico colectivo» (Gil Casado, 1975: 46 y 47).

Esta especificidad en el tratamiento del personaje y, en especial, el que fuera obrero, campesino, emigrante, inmigrante o cualquier habitante de área desolada de la geografía española o marginal de una gran ciudad, en un primer momento, para tratar, entrados en los sesenta, en la burguesía inoperante, acomodada y enriquecida con el estraperlo de la posguerra y los lucrativos negocios que el reciente proceso de capitalización les ofrece a destajo, ha conducido a críticas, como la de Sanz Villanueva (1980), a considerar este aspecto como uno de los mayores errores de este realismo, ya que conducía a lo que él llama «el acusado maniqueísmo» (1980: 199) de muchos de estos libros, si bien resalta, de entre esta galería de personajes, lo que denomina como héroe abandonado, del que dice que: «el protagonista se encuentra arrojado en la sociedad, sin posibilidad de actuación social, lo que le hace refugiarse en la soledad del yo» (Sanz Villanueva, 1972: 218) (Álamo Felices, 1996: 181-182). 
La otra queda ligada a planteamientos filosóficos como el existencialismo. Recordemos que:

Para el existencialismo la existencia humana no se sustenta en un principio intemporal y eterno, sino que consiste, justamente, en un devenir, en un perpetuo hacerse en el tiempo. La existencia, como libertad, es radical contingencia, fluctuando entre la posibilidad de ser y de no ser. Diferente a todos los demás seres del universo, el hombre es el único que tiene que actualizar su existir en un proceso constante y dinámico de autocreación. De ahí la angustia, concepto fundamental de todo el existencialismo, dilucidado por Kierkegaard en su tratado El concepto de la angustia (Roberts, 1978: 15).

Este sería, por tanto, el panorama en el que se encuentran los personajes de novelas como La náusea (1938), de J.-P. Sartre, de dramatizaciones como Esperando a Godoy (1952), de S. Beckett, y, en España, la galería de seres atormentados, enajenados, fracasados y con la muerte como vocación que pueblan la obra de novelistas de nuestra primera posguerra como Ignacio Aldecoa, José Luis Castillo Puche, Miguel Delibes, Alejandro Núñez Alonso, entre otros.

Por otro lado, el desarrollo de la ciencia moderna y contemporánea y, junto con ella, la profusión literaria del subgénero novelesco de la ciencia-ficción la cual, dentro de su configuración temática, desarrolla un tipo especial de personaje al que se le puede atribuir determinadas características del prototipo de héroe clásico:

A pesar de todo, no faltan críticos que, como Ferreras (1972: 164 y ss.), hablan de un nuevo héroe -basándose en el héroe romántico-, un héroe que sería fruto de la evolución, un mutante dotado de cualidades especiales, que entra en conflicto con su universo por ser diferente. Por su deseo de hacer el bien y de sacrificarse, este héroe, a pesar del rechazo de los humanos que intentan eliminarle, puede ascender a la categoría de mito. Su objetivo final, más que la conquista de nuevos mundos o el poder, será la búsqueda de su propia identidad (Pulido, 2004: 44-45).

Pues bien, frente a las tan significativas muestras anteriores de clasificación y de definición del término héroe, M. Bal (1990) incide, por su parte, en que todos estos intentos reflejan un claro fracaso, ya que, si se comparan entre sí, se adolece de unanimidad y de un mínimo paralelismo teórico-conceptual con lo que se necesita, afirma, un intento de sistematización de criterios, postulado Bal, entonces, un programa de cinco puntos en el que se describe las maneras en que un personaje puede «sobresalir» de manera más determinante que el resto en una narración:

- Calificación: Información externa sobre la apariencia, la psicología, la motivación y el pasado.

- Distribución: El héroe aparece con frecuencia en la historia, su presencia se siente en los momentos importantes de la fábula.

- Independencia: El héroe puede aparecer solo o tener monólogos. 
- Función: Ciertas acciones sólo le competen al héroe: llega a acuerdos, vence a oponentes, desenmascara a traidores, etc.

- Relaciones: Es el que más relaciones mantiene con otros personajes (Bal, 1990: 100).

Sin embargo, M. Bal, propone, por lo demás, una distinción entre las figuras, denominadas por esta gran narratóloga, héroe activo y con éxito frente al héroe víctima y el héroe pasivo: «[...] el héroe víctima se enfrentará con sus oponentes pero no los vencerá. El antihéroe difícilmente se distinguirá por esta función, porque es pasivo. Sí cumpliría, sin embargo, los otros cuatro criterios» (Bal, 1990:100).

En la actualidad, el concepto del héroe contemporáneo está centralizado en el análisis de personajes particulares, concebidos desde un ideologismo individualizador, y poco relacionados, o insertos, en la realidad. Se trata, por consiguiente, de figuras arquetípicas, ligadas a la imaginación colectiva, y propias de la cultura de masas que se obtienen, por tanto, de la literatura popular, del cómic y, especialmente, del cine más comercial:

Según Abbagnano, la concepción romántica de la historia, estructurada sobre la creencia de que la misma está encaminada a realizar un plan perfecto e infalible y existen individuos destinados a realizar ese plan, ya no tiene vigencia alguna $\left[{ }^{10}\right]$. Sin embargo, resulta obvio que todavía está presente en una gran parte del público contemporáneo, que no únicamente proyecta esta percepción en la forma como percibe las películas, sino incluso la utiliza para «leer» la realidad misma. En realidad, el cine a menudo no viene siendo sino la puesta en escena de una concepción ideológica ampliamente difundida (Velasco, 2000: versión informática).

II. El concepto de antihéroe ( o antisujeto, según Prince, 1987), por otra parte, es utilizado en Narratología y en teatro desde una doble perspectiva:

[...] para referirse al antagonista $\left[{ }^{11}\right]$, que se opone o lucha contra el personaje central de la trama en una determinada obra literaria, o bien para designar al protagonista al que se ha privado de las cualidades con las que habitualmente se presenta al héroe en la tragedia clásica, en los relatos fantásticos, en los cuentos y en las novelas de aventuras (belleza, juventud, valor, nobleza, etc.) (Estébanez Calderón, 1999: 40).

\footnotetext{
${ }^{10}$ «Ciertamente la sociedad estadounidense, con su visión "democrática”, ha eliminado en gran parte este aspecto de nobleza del origen de sus héroes (sin embargo, se dan todavía casos donde se recurre al tema tradicional del hijo ilegítimo o abandonado), presentándolos a menudo como individuos comunes o corrientes, o incluso pertenecientes a las estructuras más bajas de la sociedad (de donde se eleva gracias a sus dotes especiales)» (Velasco, 2000: versión informática).

${ }^{11}$ «Etimológicamente, del griego "el que lucha en contra", por lo que en narratología se usa comúnmente para referirse al papel antitético al del héroe; antagonista, pues, sería, el oponente greimasiano y el villano/agresor de Propp y es también, y en correspondencia con los anteriores, el término específico utilizado por Bourneuf y Ouellet (1972) aclimatando el modelo de las fuerzas dramáticas de Souriau al texto narrativo» (Valles, 2002: 225).
} 
Su presencia literaria se consolida con la novela picaresca y en diversas obras del siglo XVIII como La historia de Tom Jones, expósito (1749), de H. Fielding, o Moll Flanders (1722), de D. Defoe. En la literatura contemporánea aparecen, también, como protagonistas seres anodinos, grises e irrelevantes, unas veces degradados, otras reflejados de forma paródica que, en ocasiones, reflejan su desprecio o rebeldía frente a la sociedad dentro de la que o bien se les repudia o toman, incluso, la drástica opción de autoinmolarse como acto extremo liberador. Recordemos así a personajes como el Inmoralista de A. Gide, a Leopold Bloom (en el Ulises, 1922, de Joyce), a Mersault (en El extranjero, 1942, de A. Camus) o a Max Estrella (en Luces de Bohemia, 1920, de Valle-Inclán). También, algunos de estos antagonistas se han hecho casi tan famosos como los protagonistas a los que se enfrentan en sus novelas: es, por ejemplo, el caso del doctor Moriarty con respecto a Sherlock Holmes en varios de los relatos de A. Conan Doyle.

Ahora bien, la posición que ocupa el antihéroe en la estructura narrativa, desde un punto de vista funcional, viene a coincidir con la del propio héroe, ya que aquél realiza las mismas acciones que el protagonista y se mueve dentro de las mismas estructuras espacio-temporales de la trama:

La peculiaridad del antihéroe surge de su configuración sicológica, moral, social y económica, normalmente traducida en términos de descalificación. En este aspecto, el estatuto del antihéroe se establece a partir de una desmitificación del héroe, tal como lo entendieron el Renacimiento y el Romanticismo; del mismo modo, la transición de la epopeya a la novela, banalizando la figura del protagonista y presentándolo con frecuencia con defectos y limitaciones, constituyó también un factor de desvalorización que ha de tenerse en cuenta. Presentado como personaje traspasado de angustias y frustraciones, el antihéroe concentra en sí los estigmas de épocas y sociedades que tienden a aislar al individuo [...]. Fue sobre todo la literatura posromántica la que consagró a esta figura como polo de atracción y vehículo de representación de los temas y problemas de su tiempo (Reis, 1996: 23-24).

Y ampliando estas perspectivas desde un foco ideológico, imprescindible, por lo demás, para la correcta correlación/oposición narratológica de fuerzas estructurales, compositivas y actuantes del héroe/ antihéroe, puede señalarse que:

En los combates del héroe se manifiestan los enredos de la sociedad. Por ello, la definición del héroe siempre es ideológica, y la idea de antihéroe solamente es posible en oposición directa a los fines por los cuales lucha el protagonista. Para ser realmente efectivo, el antihéroe debe ser el doble o equivalente del héroe. Eso es también muy visible en muchas películas, donde el enemigo del protagonista se equipara constantemente con una especie de encarnación demoníaca, un Satán (es decir, un adversario en el sentido etimológico de esta palabra) a menudo interpretado por un actor tan famoso como quien interpreta al héroe (Velasco, 2000: versión electrónica).

Así pues, queda claro que la diferencia fundamental entre el héroe y el antihéroeo antagonista puede reducirse a su impostación ante la vida: el héroe se presenta orgánico 
y sin contradicciones, el antihéroe, sin embargo, se construye desde la contradicción y la disfuncionalidad con su época. En conclusión:

El héroe encarna sin duda unos valores y el antihéroe no, luego es técnicamente un no-héroe con relación a todos los valores patrón, pero ese absoluto lo convierte una circunstancia en un malvado o un bufón despreciable sino tan sólo en un ser que se rige por valores alternativos que el escritor puede asumir e incluso tratar de inculcar a sus lectores. Para entender el funcionamiento lógico de categorías como las de héroe y antihéroe conviene tener presente que sus contenidos respectivos son valores y que al usar el término antihéroe conviene tener presente que sus contenidos respectivos son valores y que al usar el término antihéroe estamos tomando tácitamente una postura en el latente conflicto de valores, i. e., asumimos como valores por antonomasia unos (los de la clase dominante, por ejemplo) y convertimos a los valores alternativos en «carencias» o «negatividades» lo cual es naturalmente arbitrario. Por eso, en realidad, el concepto de antihéroe es en último término superfluo y tendencioso y podemos arreglarnos perfectamente con el de héroe (siempre que estemos dispuestos a reconocer el pluralismo de valores, claro está, y con él el auténtico carácter de esa oposición de categorías) (González Escribano, 1981-82: 377).

\section{Referencias bibliográficas}

ABBAGNANO, N. (1987): Diccionario de filosofía. México, FCE.

ABIRACHED, R. (1978): La crisis del personaje en el teatro moderno. Madrid, Asociación de directores de escena en España, 1994.

AGUIRRE ROMERO, J. (1996): «Héroe y sociedad: El tema del individuo superior en la literatura decimonónica», en www.ucm.es/info/especulo/numero3/index.htm (última consulta, 1 de marzo 2012).

ÁLAMO FELICES, F. (1996): La novela social española. Conformación ideológica, teoría y crítica. Almería, Universidad.

AZIZA, C., OLIVIÉRI, C., y SCTRICK, R. (1978): Dictionnaire des types et des caractères littéraires. París, F. Nathan.

BAJTíN, M. (1970): La poétique de Dostoievski. París, Seuil. (1978): Teoría y estética de la novela. Madrid, Taurus.

BAL, M. (1990): Teoría de la narrativa (una introducción a la narratología). Madrid, Cátedra.

BOURNEUF, R., y OUELLET, R. (1972): La novela. Barcelona, Ariel, 1985.

CAPPELlO, G. (2007): «Configuración y tiempo del antihéroe», Contratexto Digital, 6.

CASARIEGO, N. (2000): Héroes y antihéroes en la literatura. Madrid, Anaya.

DUCROT. O. y SCHAEFFER, J. M. (1998): Nuevo diccionario enciclopédico de las ciencias del lenguaje. Madrid, Arrecife.

CHEVALIER, J. (2000): Diccionario de símbolos. Barcelona, Herder.

CORREA, G. (1977): «El héroe en la picaresca y su influencia en la novela moderna española e hispanoamericana», Thesaurus: Boletín del Instituto Caro y Cuervo, XXXII, pp. 75-94. 
CRESPÍN ARGAÑARÁZ, A. (2009): «El antihéroe en la novela El juguete rabioso de Roberto Artl», en www.revistadeletras.net/el-antiheroe-en-la-novela-el-jugueterabioso-de-roberto-arlt (última consulta, 1 de marzo 2012).

DE DIEGO, R. (2000): «Sobre el héroe decadente», Thélème: Revista Complutense de Estudios Franceses, 15, pp. 57-68.

ESTÉBANEZ CALDERÓN, D. (1999): Diccionario de términos literarios. Madrid, Alianza.

FEENEY, D. C. (1986): «Epic hero and epic fable», Comparative literature, 38/2, pp. 137-158.

FERRERAS, J. I. (1972): La novela de ciencia ficción. Interpretación de una novela marginal. Madrid, Siglo XXI.

FRYE, N. (1957): Anatomía de la crítica. Caracas, Monte Ávila, 1977.

GIL CASADO, P. (1975): La novela social española (1920-1971). Barcelona, Seix Barral.

GLIFO Equipo (1999): Diccionario de termos literarios (A-D), en www.usc.es/ fedario/docs/investigacion.html (última consulta, 1 de marzo 2012).

GOLDMANN, L. (1970): Pour une sociologie du roman. París, Gallimard.

GONZÁLEZ ESCRIBANO, J. L. (1981-82): «Sobre los consejos de "héroe y antihéroe" en la Teoría de la Literatura», Archivum: Revista de la Facultad de Filología, 31-32, pp. 367-408.

GRAY, M. (1984): A Dictionary of Literary Terms. Singapore, Longman, 1997.

GREIMAS, A. J. (1966): Semántica estructural. Investigación metodológica. Madrid, Gredos, 1971.

(1970): En torno al sentido. Madrid, Fragua, 1973.

HEGEL, F. W. (1835): Estética, Buenos Aires. Siglo XXI, 1983.

LUKÁCS, G. (1916): Teoría de la novela. Barcelona, Grijalbo, 1975.

MARCHESE, A. y FORRADELLAS, J. (1994): Diccionario de retórica, crítica y terminología literaria. Barcelona, Ariel.

PRINCE, G. (1987): Narratology: The Form and Functionning of Narrative. Berlin, Mouton.

PROPP, V. (1928): Morfología del cuento. Madrid, Fundamentos, 1977.

PULIDO TIRADO, G. (2004): «La especulación científica en literatura. Para una teoría de la narrativa de ciencia ficción», Discurso, 18, pp. 27-48.

REIS, C. y LOPES, A.C. (1996): Diccionario de Narratología. Salamanca, Ediciones Colegio de España.

ROBERTS, G. (1978): Temas existenciales en la novela española de postguerra. Madrid, Gredos.

RODRÍGUEZ GÓMEZ, J. C. (1994): La Literatura del pobre. Granada, Comares. 
Introducción a la configuración narratológica de los conceptos de héroe y antihéroe

SALINAS, P. (1946): «El "héroe" literario y la novela picaresca española», Revista de la Universidad de Buenos Aires, IV, pp. 75-84.

SELDEN, R., WIDDOWSON, P. y BROOKER, P. (2001): La teoría literaria contemporánea. Barcelona, Ariel.

VALLES CALATRAVA, J., dir. (2002): Diccionario de Teoría de la Narrativa. Granada, Alhulia.

VELASCO, A. (2000): «El sueño de los héroes en el cine estadounidense contemporáneo», en www.infoamerica.org/articulos/v/velasco_arnulfo.htm (última consulta, 1 de marzo 2012).

VILlEGAS, J. (1978): La Estructura Mítica del Héroe en la Novela del Siglo XX. Barcelona, Planeta. 